\title{
1 The application of quality control charts for identifying changes in time-series home \\ 2 energy data
}

3 José-Luis Vivancos ${ }^{\mathrm{a} *}$, Richard A. Buswell ${ }^{\mathrm{b}}$, Paula Cosar-Jorda ${ }^{\mathrm{b}}$, Carolina Aparicio-Fernández

$4 \quad$ Abstract

5 Energy consumption in the home is heavily influenced by the occupants and the routines they adopt. Although

6 these routines tend to be regarded as somewhat static in nature, more recent evidence from the social sciences

7 suggests that patterns of consumption are actually more fluid and constantly evolve to accommodate the contingencies of everyday living. This makes detecting changes in patterns of activity and their impact on energy consumption difficult, particularly when these patterns are often invisible to the householder to begin with. Being able to identify when a change occurs, therefore, could be a powerful tool to establish the context of change and so to determine more appropriate corrective action to curb waste and create opportunities for greater flexibility in consumption. The growing adoption of smart meters and home energy monitoring provide a platform for numerical approaches, yet there is little work reported in the literature and none that have attempted to evaluate effectiveness of such methods applied to detect changes in behaviour using field monitoring data from family homes. This paper reports on the application of a Change Point Detection method based on statistical quality control charts applied to identify changes in activities a family home using typical monitoring data. The approach was found to be very effective, identifying $78 \%$ of the changes that occurred over a two-year period and hence the outlook for such methods is promising. The findings suggest that such techniques could significantly improve the quality of information provided in energy feedback and so could play a significant role in the pursuit of more efficient energy use in the home by adding value to monitoring systems and services.

\section{Keywords}

domestic monitoring data; appliances; changes; occupancy; statistical quality control; family homes

\section{Introduction}

Reducing energy consumption in the home can be achieved either through gains in efficiency or curtailment of consumption [1]. The former includes measures such as improving insulation levels

\footnotetext{
a jvivanco@dpi.upv.es, Department of Engineering Projects, Universitat Politècnica de València, Spain

* Corresponding author: José Luís Vivancos, jvivanco@dpi.upv.es, Department of Engineering Projects, Universitat Politècnica de València, Spain

b r.a.buswell@Iboro.ac.uk, School of Architecture, Building and Civil Engineering, Loughborough University, UK p.cosar@lboro.ac.uk

c caap@csa.upv.es Universitat Politècnica de València, Spain
} 
and the latter reducing the level of comfort and convenience offered by systems and appliances, such as turning down the thermostat on the heating system [2]. The introduction of Smart Meters and monitoring and feedback technology in the home present significant opportunities to augment curtailment in the home despite the observed variation in impact of reduction measures [3]. The recognition that demand reduction in the home is multi-disciplinary problem has led to significant steps forward in understanding the complexity of addressing the issue in practice [4]. Making links between what is often termed 'behaviour' and consumption in an empirical sense is important [5] yet challenging: studies often report of significant variation in derived quantities and relationships in the home, of which [6] (ventilation) and [7] (space-heating) are just two of many.

The motivation for this work comes out of a four-year multi-disciplinary project investigating energy demand reduction in the home where social scientists and engineers worked together to investigate practices and routines in the home alongside longitudinal energy and appliance monitoring [REF BRI Paper]. This led to understanding the home to be a place of adaption and change, driven by the contingencies of everyday living [8], rather than the more static representations usually found in modelling and simulation exercises [9]. The pressure on householders to complete critical tasks often outweighs other considerations and because the home is a busy environment, it is not unsurprising that good intentions towards system and appliance use tends to get lost in the day-to-day 'noise' [10]. It is therefore challenging for anyone except the motivated, energy aware and system savvy to keep on top of the effect of efforts to curtail consumption as well as the development of less desirable consumption habits forming.

The central idea developed and tested in this work is whether or not typical smart home monitoring data can be used to identify changes in behaviour. Being able to identify changes in consumption in (close to) real time enables flags to the householder that would provide them a timely point for refection, to reconcile the causal factors and take corrective action as they choose. In this work we apply unsupervised Change Point Detection methods [11] to time-series data which results in a scalable approach to coupling behaviour to smart meter and smart home system data. This offers the opportunity of tailoring energy information for individual householders, which is likely to improve 
energy curtailment [12] and support the development of energy services around the use of Artificial

54 Intelligence and data analytics to more efficient use of national energy systems [13].

\section{Background}

56 Meeting national $\mathrm{CO}_{2}$ reduction targets [14] will continue to shape the future energy landscape

57 resulting in less reliance on fossil fuels and an increasing generation from renewable sources.

Providing flexibility of demand in the future and the increased use of storage in order to match supply is likely to become as important as reducing demand itself [15]. There can be no doubt as to the significance of the role energy demand in the residential sector will play in the future provision of energy: in the UK this accounts for $29 \%$ of the nations' energy consumption [16], in Europe 40\% [17] and $21 \%$ in the US [18].

Reducing energy demand by curtailment of demand has been the subject of many field trials in recent years $[3,19]$. The impact of these approaches has been variable and led to the methodological frameworks of many studies being questioned and the development of better practice [2,20-23]. The 'unpredictable' nature of household energy performance may well be influenced by the constantly evolving nature of the home where appliances and systems are used in response to the contingencies of everyday life $[4,24]$. The variation of impact of curtailment is particularly evident in observations from energy feedback trials $[25,26]$ and tailoring information for specific householders has shown to be both effective [27,28], and potentially scalable alongside deployment of 'smart home technology' [29].

Identifying changes in the attitudes of householders towards energy consumption has been studied through the application of psychology and sociology [12] and it has been shown that learning is an important component in curtailment activities [31]. Often 'daily life' takes precedent over the achievement or interest in energy goals [32] and so monitoring combined with numerical methods have the potential to shine a light through the murk of home energy consumption. The use of numerical methods to determine when changes occur in the household could offer new possibilities for:

- continual real-time monitoring of the impact of reduction measures; 
- identification of new emergent behaviour in the household; and,

- increase information from monitoring data to improve change analysis.

Such applications fall into two categories. The majority of the work in buildings lies in Fault Detection and Diagnosis (FDD), usually applied to monitoring the condition of heating ventilation and air conditioning equipment [33,34]. Beginning in the 1990's, the work is still current, although these methods are typically applied to thermo-electrical or mechanical processes, where some notion of 'correct operation' is provided by an idealised model against which measurements from the actual system are compared to.

Although the modelling the behaviour of building occupants is of significant interest $[35,36]$ (occupancy patterns in particular [37-39]), there has been far less work applying Change Point Detection (CPD) in building applications. CPD methods find abrupt changes in time-series data and can be found in applications such as: medical condition monitoring, climate change detection, speech and image analysis and analysis of human activity [11] . They can be divided into supervised and nonsupervised approaches.

Supervised approaches use past data to generate a model of an important attribute of the data, or class. Such methods have been readily adopted within building energy performance modelling, examples being: Decision Tree for building energy demand [40]; Hidden Markov Model for domestic energy behaviour [41]; and Logistic Regression for window opening behaviour [42]. These methods are useful for determining what class data falls into, but do require significant training data from across the anticipated operating space, and hence are particularly useful for creating input models to drive building energy simulation, once the requisite data has been collected. Unsupervised methods are applied to pattern-find in unlabelled data where the time series is segmented and statistical methods applied to test differences of which examples are: likelihood ratio [43], and clustering [44]. Understanding the patterns of energy use in the home has been of interest for some decades: mapping of data onto behaviours, or characteristics [45]; and for understanding occupancy in residential buildings in [46] are examples. Change point models have been used to identify patterns of residential air conditioning use in residential buildings [18]. Change Point Detection has been applied in the building energy field for monitoring behaviour change for health monitoring [47] in an assisted 
Living environment. In this work door, and cabinet opening was monitored as well as motion and light sensors. Activity maps for specific features were developed, sleep relax, enter home, and these were used to establish changes in behaviour and it was found that changes in routines could be detected successfully.

These applications are quite different from detecting changes in lifestyle. Applications for lifestyle change, mainly physical activity, relate to changes in behaviours to invest in the attainment of fitness goals [47-49]. Here methods are applied to time-series data, but the data streams are bound to measurements such as accelerometers, located at the wrist (for example). The metrics, or features that are searched are also constrained, the problem is to determine changes in: activity type, duration, intensity, frequency.

This is very different to the problem of detecting changes in the household, where the events are unconstrained and there is a significant choice of measurements from which to extract change features. To the best knowledge of the authors there is no work that has investigated whether Smarthome, time-series measurements are sensitive to change, which could be used for feature extraction and what types of changes can be observed. We address this gap in this work by selecting two unsupervised CPD methods, commonly used in statistical quality control [21], and apply them to time series monitoring data gathered from a family home over a 12 month period.

Self-reported change events occurring in the home over the monitoring period were used to reconcile the performance of the CPD methods. Incoming electricity, hot water consumption and appliance use were tested for their sensitivity to change and used to establish whether the identified changes were time-bound, (i.e. observed to shifting back to the priori normal state), or whether it shifts consumption to a 'new-normal' state, where consumption may be higher, or lower than before. From this analysis we draw conclusions and the outlook for such methods in this building energy monitoring application.

\section{Methodology}

In order to test the sensitivity of statistical quality control (QC) charts, a family home was monitored for two years and was also asked to report when changes occurred in the home. There were a variety of changes reported such as, holidays, maternity leave, the acquisition of new appliances, a new job 
etc. The monitoring comprised of temperature, flow rates and appliance power measurements sampled at various rates from one second to two minutes. A subset of these were selected and these measurements were then aggregated to yield two signals, one at daily frequency and the other at a weekly interval. This allowed a range of measurements at different granularities to be tested for sensitivity.

Each signal was tested for autocorrelation, in order to ensure statistical validity. Where autocorrelation was found, the ARIMA model was used to model the data and used to generate residuals, which replaced the aggregated, measured data as the signal. The approach was implemented using standard functions within the ' $R$ ' statistical package, hence accessible for others to apply the methods.

\subsection{Measurements and data collection}

Incoming mains power, appliance power and hot water consumption were selected in this study as their use has been identified as being tightly bound to the activities, routines and practices in the home [35]. The incoming mains power and electrical appliance consumption was monitored between 2012 and 2014 by a proprietary home energy monitoring system (AlertMe, that later became Hive) that recorded power consumption through current transducer and 'smart plug' devices every minute $( \pm 10 \%)$. Domestic hot water consumption was added in 2013 where an in-line flow meter and thermocouples where arranged to form a heat meter that recorded both flow and temperatures every second $( \pm 10 \%)$.

Other measurements such as room air temperature, natural gas consumption (for the space-heating and hot water system) and window position were considered, but rejected for this study because of their well reported dependencies on other factors, outside air temperature in particular [50] and remain areas for further investigation. The recorded data was pre-processed to check for missing samples and whole 24 hour periods (00:00 - 23:59) were either accepted or rejected when significant missing data was found. Full details of the processing and access to the data can be freely downloaded from [51].

\subsection{Generating the signal}


161 Two granularities of signal were investigated, aggregating the monitored data daily and weekly

162 values, giving a maximum of 730 or 104 data points respectively over the test period. A further check

163 was made to identify any periods of missing data in each signals and checks were made to ensure

164 these periods did not bias the results.

165 Three types of metrics were used to generate the signals:

166

- aggregated consumption;

167

- number of cycles or switch-on events per day; and,

- the minutes of use per day.

169 To determine the number of uses/cycles per day for an appliance the 'findPeaks' function of the 'quantmod' package in $\mathrm{R}$ was used. This function provides a vector of integers that correspond to the number of peaks found. The peaks are the highest values in the evaluated series and are found by searching for a change in the direction, so the function returns the first after the peak value is found, to avoid the introduction of look-ahead bias. Once the peaks have been identified, the aggregated values can be calculated and the signal time-series data generated.

\subsection{Testing the signals for evidence of change}

Standard quality control (QC) charts are commonly found in manufacturing and are closely related to significance testing. Here the QC method tests whether a process is in statistical control: e.g. whether the measures variations are due to stochastic noise, or whether the errors are due to an underlying problem. A null hypothesis of the process being under control is determined if the data are within the prescribed limits and rejecting the hypothesis otherwise [52].

The general theory was developed by Walter A. Shewhart and are commonly known as Shewhart control charts. The main disadvantage of the quality control charts is that they are relatively insensitive to small shifts: in the order of $1.5 \sigma$ or less. A very effective alternative to control charts is the cumulative sum or CUSUM chart. The CUSUM chart has two indicators, one that sums positive deviations (upper), and one that sums the negative (lower). The upper CUSUM accumulates deviations from the target value that are greater than half the shift $(\delta / 2)$ : it increases linearly with the number of positive deviations and with their average weight, until it crosses a predetermined limit. 
188 Similarly, when there is a negative shift, it accumulates negative deviations, and the lower CUSUM

189 linearly decreases.

190 The application of both Shewhart and CUSUM charts were implemented using the statistical software

191 tool 'R' (Version: Team R.D.C. R 3.2.3; 2016). Specifically, the 'qcc' and 'qcr' packages were used

192 to perform control chart calculations [53], and the packages 'stats' and 'forecast' (for automatic

193 fitting) has been applied to fit ARIMA (Box-Jenkins time series) models [54]. 


\subsection{Addressing autocorrelation}

QC charts are applicable when the observed processes (represented by the signal) are independent and identically distributed. Each of the signals was tested for auto-correlation using the Box test and problematic data was treated to remove the auto-correlation. Woodall and Montgomery discussed the challenge of estimating quality control limits of autocorrelated data [55]. Autocorrelation usually leads to an increase in process variability, and one of the most highly recommended methods to deal with this is to remove the sources of autocorrelation by fitting an ARIMA (Box-Jenkins time-series) model [27]. The ARIMA (auto-regressive integrated moving average) model is a time-series forecasting model that uses Auto-regression is a forecasting equation term that explains time series lags. The non-seasonal ARIMA model in R is 'ARIMA (p,d,q)', where $\mathrm{p}$ is the number of autoregressive terms; $\mathrm{d}$ is the number of non-seasonal differences; and $\mathrm{q}$ is the number of lagged forecast errors in the prediction equation.

The function 'auto.arima' within R was applied to return the best ARIMA model for the specific signal, according to the Akaike Information Criterion, which is an estimator of the relative quality of statistical models for a given set of data. The model is fitted to an initial proportion of the data, and determines the initial 'normal' state of the system. The ARIMA model is then used to predict subsequent data points and the residual is calculated, this residual then replaces measured data as the signal, and in most cases the residual time-series is subject to random variation and as such is not auto-correlated and can be used with the QC charts.

\subsection{Identifying changes}

Each signal was then evaluated and the changes were identified in the data. These were then compared to the self-reported data to verify the method.

\section{The household and observed change}

The data was collected from a brick built, semi-detached building (one wall connecting it to the neighbouring property), constructed in the 1990's with loft and cavity wall insulation and double glazing throughout. The space-heating and hot water is supplied via a combination boiler. The building floor area is approximately $120 \mathrm{~m}^{2}$ and the plans are presented in Fig. 1. A family of seven 
221 people live there, with at least one adult at home during weekdays. The family comprised of the

222 grandmother, (GFA), the female adult (FA), the male adult (MA) and three children (mc1, mc2 and

223 fc3). A new baby arrived during the monitoring period.

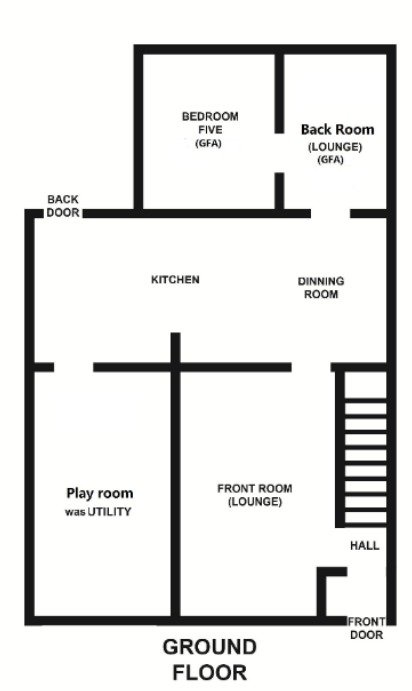

REAR

225 Fig. 1. Floor plans of the case study building.

226 Qualitative information on the changes occurring during the monitoring period were recorded by researchers prompting householders to recollect change events. The data are presented in Table 1 and commencement and cessation of the change have been included in Table 1.

Table 1. Changes in case study building

\begin{tabular}{lllll}
\hline Ref. & Type & Description & Start date & End date \\
\hline 1 & Appliance & New dishwasher & $25 / 12 / 2013$ & \\
2 & Digital & Replacement TV (lounge) & $01 / 05 / 2013$ & \\
3 & Digital & Replacement TV (mc1 bedroom) & $25 / 12 / 2013$ & \\
4 & Fabric & New wall and window in playroom & $23 / 09 / 2013$ & \\
5 & Occupancy & Grandma away & $23 / 07 / 2012$ & $27 / 07 / 2012$ \\
6 & Occupancy & Family holiday, Grandma at home & $15 / 08 / 2012$ & $25 / 08 / 2012$ \\
7 & Occupancy & FA on maternity leave & $01 / 03 / 2013$ & $24 / 02 / 2014$ \\
8 & Occupancy & Family holiday, Grandma at home & $28 / 03 / 2013$ & $01 / 04 / 2013$ \\
9 & Occupancy & Arrival of baby & $01 / 05 / 2013$ & \\
10 & Occupancy & MA on paternity leave & $01 / 05 / 2013$ & $20 / 05 / 2013$ \\
11 & Occupancy & Grandma holiday & $27 / 06 / 2013$ & $13 / 07 / 2013$ \\
12 & Occupancy & Family holiday, Grandma at home & $15 / 07 / 2013$ & $20 / 07 / 2013$ \\
13 & Occupancy & Grandma away & $22 / 07 / 2013$ & $27 / 07 / 2013$ \\
14 & Occupancy & Children away & $25 / 07 / 2013$ & $28 / 07 / 2013$ \\
15 & Occupancy & FA away with fc3 mc4 & $26 / 07 / 2013$ & $28 / 07 / 2013$ \\
16 & Occupancy & Family holiday, Grandma at home & $23 / 08 / 2013$ & $25 / 08 / 2013$ \\
17 & Occupancy & FA restarts work mornings & $24 / 02 / 2014$ & \\
18 & Occupancy & Family holiday no one at home & $17 / 04 / 2014$ & $21 / 04 / 2014$ \\
19 & Space & Bedroom 1 divided into 2 rooms & $19 / 12 / 2012$ & \\
\hline
\end{tabular}


We found it useful to place these into broader categories that reflect: replacing or acquiring a new appliance, replacing or acquiring new digital technology, improving the building fabric, changes to occupancy, and changes to space size or use. 19 changes were recorded in total, 14 of which apply to occupancy patterns, including holidays, the birth of a baby and paternity and maternity leave.

\section{Results}

Before applying these methods, the null hypothesis of observation independence was explored using following procedure. The p-value measures the distance between the data and the null hypothesis using an estimate of the parameter of interest. To ensure the sample size led to statistically significant p-values, sample size a criterion was established at 90 and 25 for days and weeks respectively.

Most cases obtained a p-value greater than 0.2 , which means the null hypothesis of observation independence is not rejected and hence could be independent, except for the incoming mains power where a p-value of 0.0168 was obtained. Where a p-value greater than 0.2 was obtained for measurement, autocovariance or autocorrelation function $(\mathrm{lag}=1)$ was explored to confirm independence.

Autocorrelation was found in all daily signals. Reducing the granularity of data can sometimes help minimise auto-correlation, and a weekly aggregated signal did improve the autocorrelation for both washing machine power and hot water consumption. The ARIMA model was therefore applied to generate the residuals for all other measurements. These residuals were then used as signals (Table 2).

Table 2. Box-Pierce or Ljung-Box test statistic, Time series forecasting model.

\begin{tabular}{|c|c|c|c|c|}
\hline Measurement & Signal & Granularity & Signal Type & Forecasting Model \\
\hline \multirow{2}{*}{ Washing machine power } & \multirow{2}{*}{ Number of cycles } & Daily & Residuals & $\operatorname{ARIMA}(1,0,1)$ \\
\hline & & Weekly & Mean & - \\
\hline \multirow{4}{*}{ Lounge TV power } & \multirow{2}{*}{ Consumption } & Daily & Residuals & $\operatorname{ARIMA}(4,1,4)$ \\
\hline & & Weekly & Residuals & $\operatorname{ARIMA}(0,1,1)$ \\
\hline & \multirow{2}{*}{ Minutes of use } & Daily & Residuals & $\operatorname{ARIMA}(3,1,3)$ \\
\hline & & Weekly & Residuals & $\operatorname{ARIMA}(0,1,1)$ \\
\hline \multirow{2}{*}{ Kettle power } & \multirow{2}{*}{ Number of switch } & Daily & Residuals & $\operatorname{ARIMA}(1,1,1)$ \\
\hline & & Weekly & Residuals & $\operatorname{ARIMA}(0,1,1)$ \\
\hline \multirow{2}{*}{ Incoming mains power } & \multirow{2}{*}{ Consumption } & Daily & Residuals & $\operatorname{ARIMA}(1,1,1)$ \\
\hline & & Weekly & Residuals & $\operatorname{ARIMA}(1,1,1)$ \\
\hline \multirow{2}{*}{ Hot water volume } & \multirow{2}{*}{ Consumption } & Daily & Residuals & $\operatorname{ARIMA}(3,0,3)$ \\
\hline & & Weekly & Mean & - \\
\hline
\end{tabular}


The upper plot in Fig. 2 shows CUSUM chart from model ARIMA $(3,0,3)$ with non-zero mean model

252 for daily hot water consumption where the first 90 days were used to determine the control limits

253 (normal operation). The weekly hot water consumption is presented in the lower plot in Fig. 2.
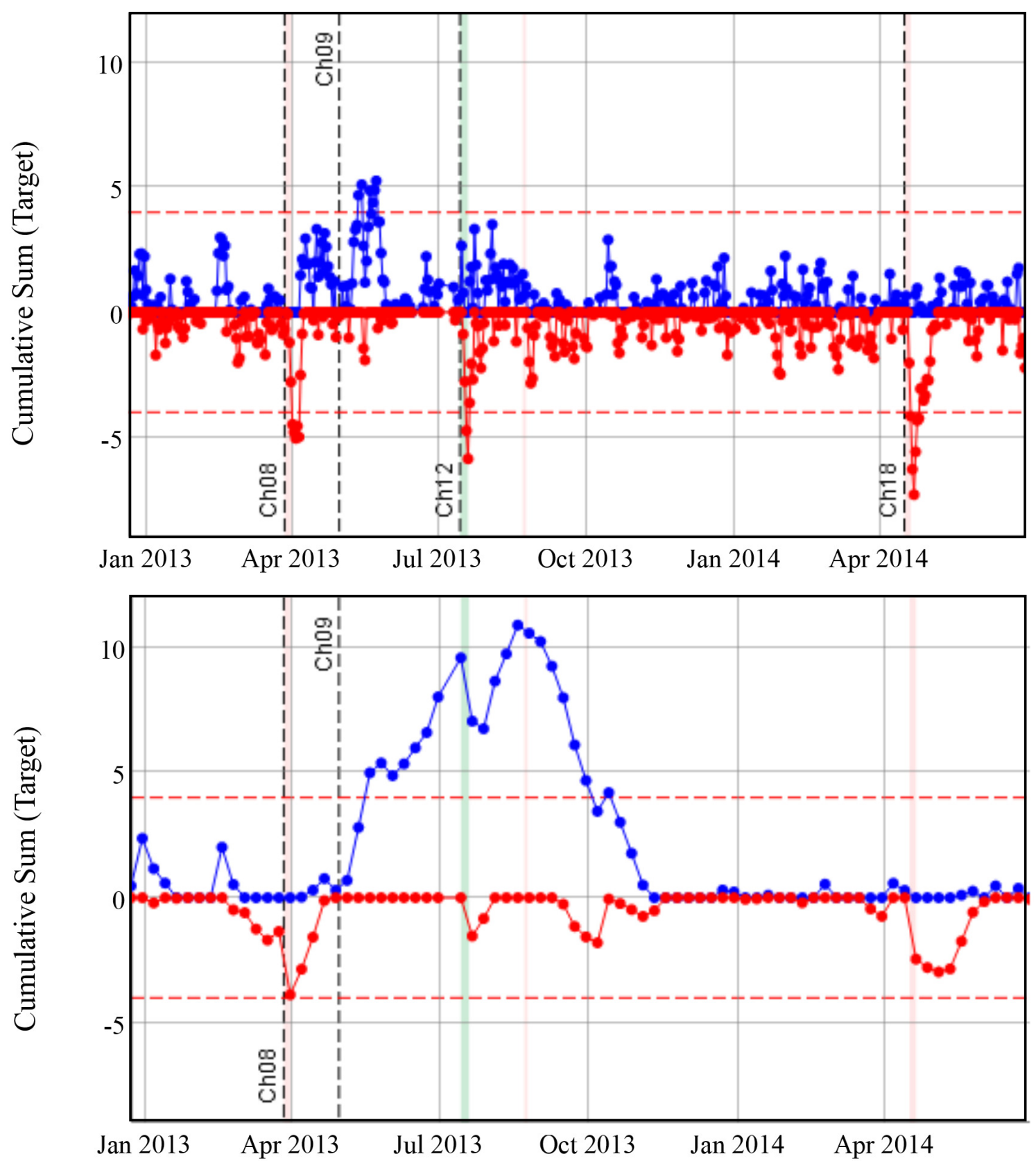

Fig. 2. CUSUM chart for the consumption of hot water in litres per day (top) and the weekly mean litres per day (bottom). A value of 0.0 on the y axis means agreement with the ARIMA model, and indicates 'normal operation', deviations are cumulatively summed in both the positive (blue) and negative (red) directions. Changes are noted with vertical black dashed lines and relate to Table 1. 
The plots in Fig. 2 depict the cumulative positive and negative increase (blue and red lines respectively). The horizontal line at 0.0 indicates a residual of zero, hence agreement with the model, equivalent to 'normal operation'. The red dashed lines at 4 and -4 are the change decision limits, beyond which the method indicates change.

The vertical dashed lines show when change events were reported (Table 1: changes 8, 9, 12 and 18 respectively). Time-bound changes relating to vacation periods (Table 1: changes 8, 12 and 18) are indicated but a shaded section relating to the affected period. The event driven change (Table 1: change 9) is shown as a single line.

The vacation periods were correctly identified in Fig. 2. differ in nature. The changes 8 and 9 (Table 1) were vacations where the elderly relative remains home and change 18 , the house was empty: there is a greater decrease evidenced in the latter. In the lower plot of Fig. 2, however these changes are insufficient to be identified as changes using the weekly aggregated consumption and the indicator. The arrival of a new baby, change 9 is identified by both signals, but there is a three-week lag in the weekly aggregated values, and there is a significant difference in the return to the normal state. The upper plot in Fig. 3 shows CUSUM chart of residuals from model ARIMA $(1,1,1)$ for the daily number of kettle uses, where the first 32 days were used to determine control limits (normal operation). Similarly, to the hot water consumption, a sharp increase identifies the arrival of the new baby (Change 9) and a decrease identifies the family vacation (Change 12). Unlike the hot water signal, changes 8 and 9 were not identified, but changes 6 and 19 were even though change 6 appears to be similar to change 8 .

\subsection{Summary of identification of changes}

Table 3 provides an overview of the results across all signals tested. The blocks indicate successful identification. Those with a white dot highlight changes occurring at the same time: changes 9 and 10 have, hence been counted as one change (arrival of new baby and paternity leave). The dashes indicate changes that occurred before the hot water monitoring was installed, and hence do not contribute to the hot water signal performance. The identification rate of each signal and the 

identification if all indicators were used.
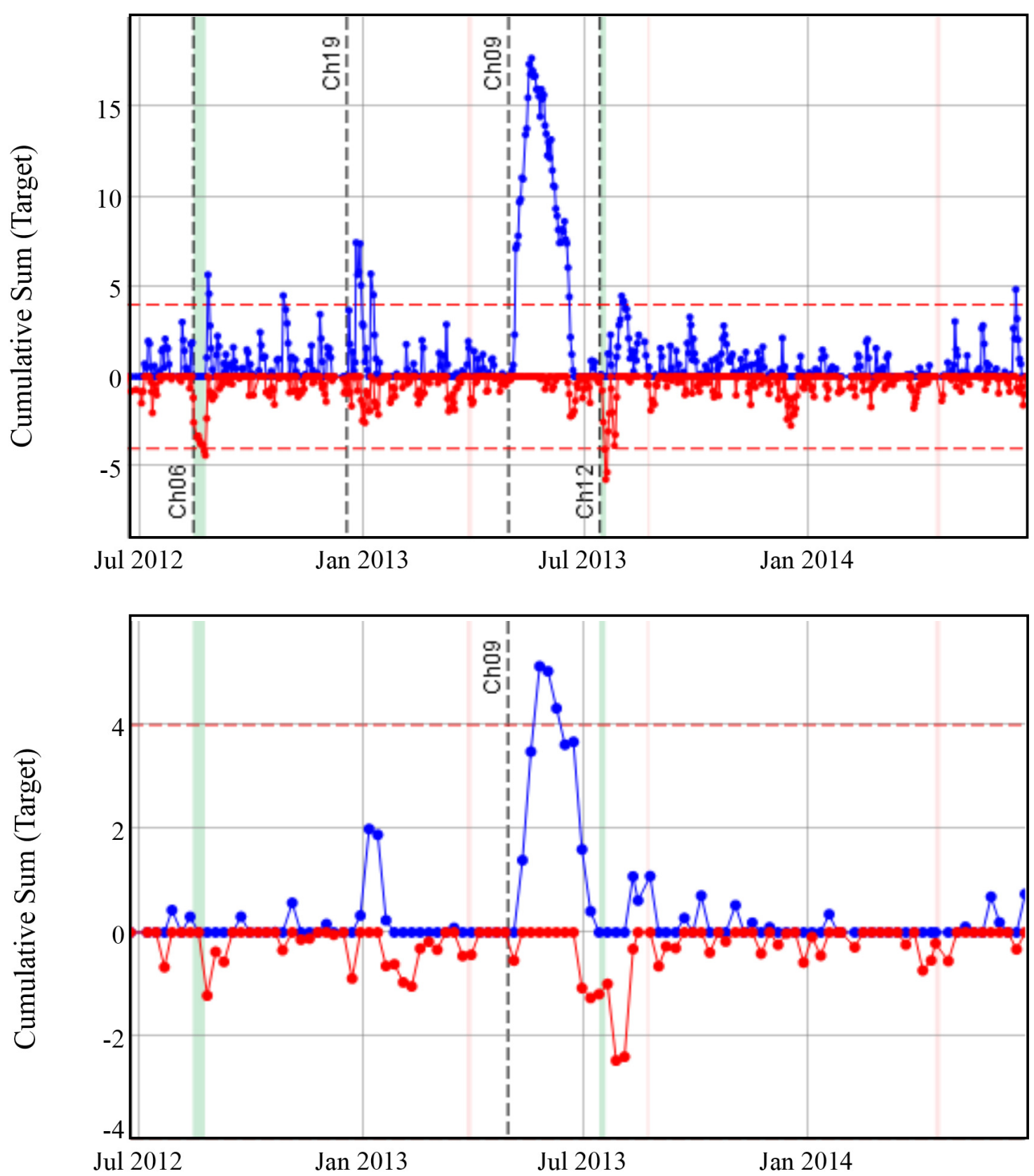

Fig. 3. CUSUM chart for the kettle use measured in numbers of switch-on events per day for the whole monitoring period (top), and for the weekly mean switch-on events (bottom). A value of 0.0 on the y axis means agreement with the ARIMA model, and indicates 'normal operation', deviations are cumulatively summed in both the positive (blue) and negative (red) directions. Changes are noted with vertical black dashed lines and relate to Table 1. 
293

294

295

296

297

298

299

300

301

302

303

304

305

306

307

308

309

310

311

312

313

314

315

316

317

318

319

15 out of 19 changes listed in Table 1 (18 unique) were identified by performing statistical analysis using signals based on the five measurements detailed in Table 2 . In the following text, the change is referenced by a number in parenthesis.

The most successful signal was the kettle. The kettle identified 8 changes, 7 unique, as can be seen in Table 3. The arrival of a new baby (change 9), which is coincident with the paternity leave, was detected by both weekly and daily patterns of kettle use and both daily and weekly domestic hot water usage. The summer family holiday in 2013 (change 12) was detected by the Kettle daily patterns but also by the TV minutes of use. Interestingly, only two signals detect the summer holiday in 2013 (change 12), whereas the summer holiday in 2012 (change 6) was detected by 5 signals: daily TV power consumption and minutes of use, incoming electrical power consumption, kettle number of switch-on events and weekly number of washing machine cycles.

Occupancy changes that involve only one person leaving the house were uniquely detected by the kettle (changes 13, 14 and 15). And the building work required to divide one of the rooms in two (change 19) was detected by 4 signals: the daily number of washing machines, the kettle, the incoming power both daily and weekly.

The number of washing_machine cycles indicated four changes, being the strongest predictor together with incoming electrical power consumption, after the kettle. One of the identified changes occurred when the new wall and window were installed in the playroom (change 4), being detected by the daily aggregate signal. Another change detected by the daily washing machine usage was FA going back to work (change 17), apart from changes 6 and 19 as it is staged above. Incoming electrical power consumption was capable of identifying both daily and weekly the acquisition of a new dishwasher (change 1) and the Easter family holiday (change 18), also changes 6 and 19.

The volume of daily domestic hot water consumed identified three changes including: the 2013 Easter holiday (change 8), which was identified using both daily and weekly signal granularities; the Easter holiday in 2014 (change 18); and the arrival of a new baby (changes 9 and 10). The daily aggregate 'TV minutes of use' signal and the 'power consumption' signal both use the TV power consumption measurement, but yielded different results and both a daily and weekly aggregate level. 
was causing the detected outlier cannot be determined, or whether it was caused by the combination of changes or one in isolation. The same issue occurred with changes 9 and 10 , as when the new baby arrived: father (MA) went on paternity leave. Also, new patterns of hot water consumption developed since baby arrived and persisted such that they potentially affected the second summer holiday period in 2013 (change 12) is still obscured by the arrival of the baby.

Table 3. Decisions taken using scheme presented above and changes detected for values analysed.

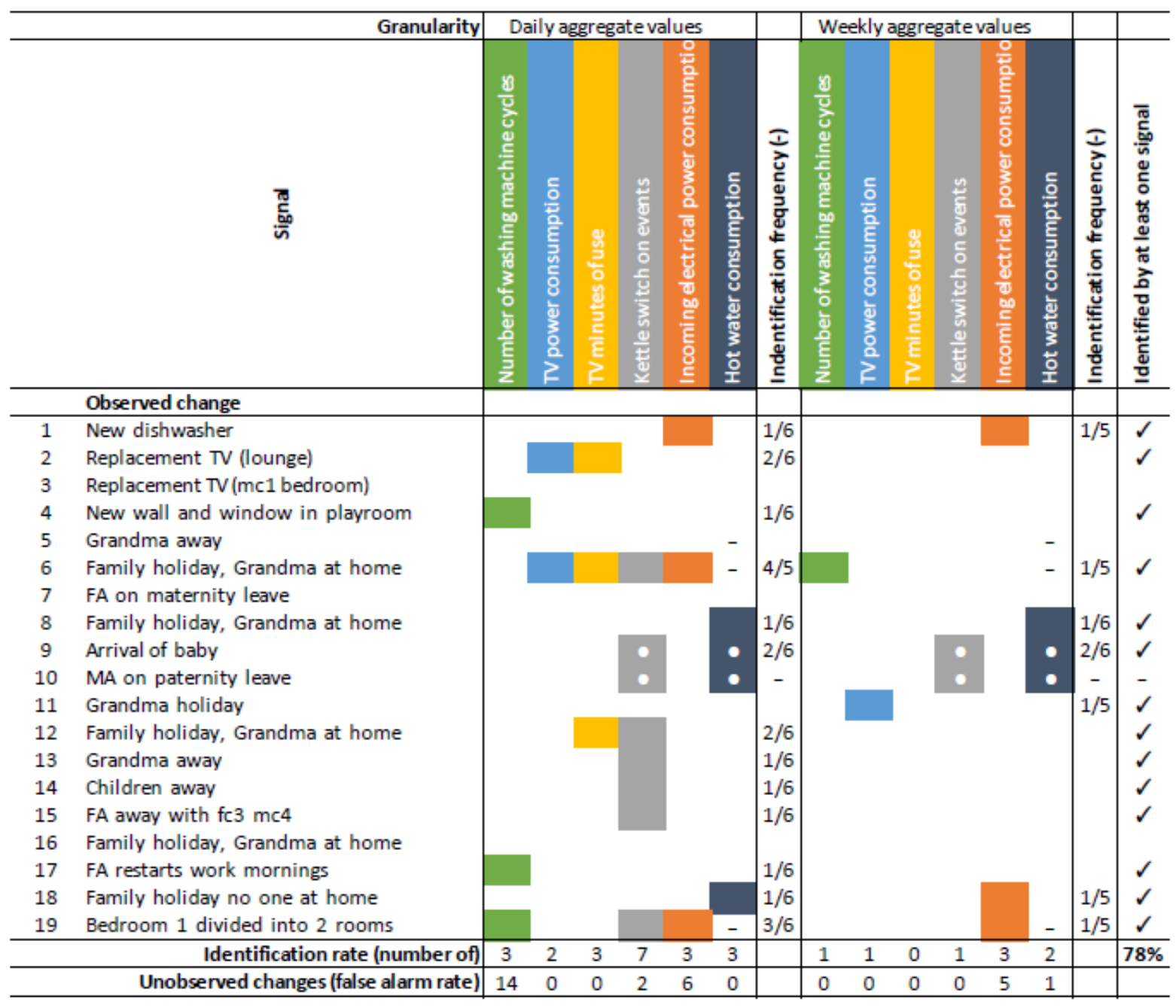
mc1 room (change 3), the vacancy of the grandmother during July 2012 (change 5), the mother (FA) going into maternity leave (change 7), and the family summer holiday in 2013 (change 16). 
Table 3 also presents what might be regarded as 'false alarm' rates for each indicator, where the method indicated a change, but there was none reported by the householder. The washing machine was the most susceptible to this, and the daily aggregated values were more sensitive that the weekly values. The incoming mains power generated six false alarms and kettle only two. There are two things to consider: one, these 'false alarm' rates may actually be unreported changes occurring; and, importantly, these are extremely low false alarm rates. The power measurements for example, were collected over two years, which at worst is less that one false alarm every two months and is likely to be less than one per year, indicating that these methods are robust, while being sensitive to changes.

\subsection{Returning to the normal state}

There are two potential states that can occur post change: that the household returns to its normal operating state; or that the event changes the level of consumption. because we found the signals to be highly autocorrelated, we used residuals which vary about a zero mean, and so a secondary test is required after a change has occurred to examine the state of operation pre and post change.

We considered change 6 , the family vacation and change 9 , the arrival of a new baby as examples of a time-bound and an event driven change respectively, depicted in the upper and lower plot of Fig.4 respectively. We tested the pre and post change conditions by calculating the 60 day mean of the signal either side of the change period for change 6 and the event of change 9 . The results are presented in Table 4 for all the signals that identified the change (Table 3).

Table 4. Returning to the normal state after a time-bound change (6) and returning to a new-normal state after and event (9) with higher consumption.

Returning to the normal state after a time-bound change (6)

\begin{tabular}{lcccl} 
Daily aggregated signal & $\mathbf{6 0}$ day mean before & Mean during & 60 day mean after period & Units \\
\hline TV power consumption & 2.6 & 1.5 & 2.6 & $\mathrm{kWh} /$ day \\
TV minutes of use & 549.5 & 346.1 & 549.4 & Minutes/day \\
Kettle switch on events & 5.8 & 3.1 & 5.9 & Events/day \\
Incoming electrical power & 14.2 & 11.5 & 19.9 & $\mathrm{MWh} /$ day \\
\hline
\end{tabular}

Returning to a new-normal state after and event (9) with higher consumption) Daily aggregated signal $\quad 60$ day mean before 60 day mean after 60 day mean, 60 days after

\begin{tabular}{lcccc}
\hline Kettle switch on events & 5.4 & 11.5 & 8.6 & Events/day \\
Hot water consumption & 95.5 & 121.2 & 111.4 & Litres/day \\
\hline
\end{tabular}


353 For the time bound event, the 60 day mean values are very similar either side of the change period,

354 and exhibit the expected reduction while most of the family members are away from the home (the

355 grandmother remains at home). However, with the arrival of the new baby the consumption/use of hot

356 water and the kettle increased significantly, and this change is persistent: 120 days (4 months) after

357 the event has occurred as can be seen in Fig. 4.
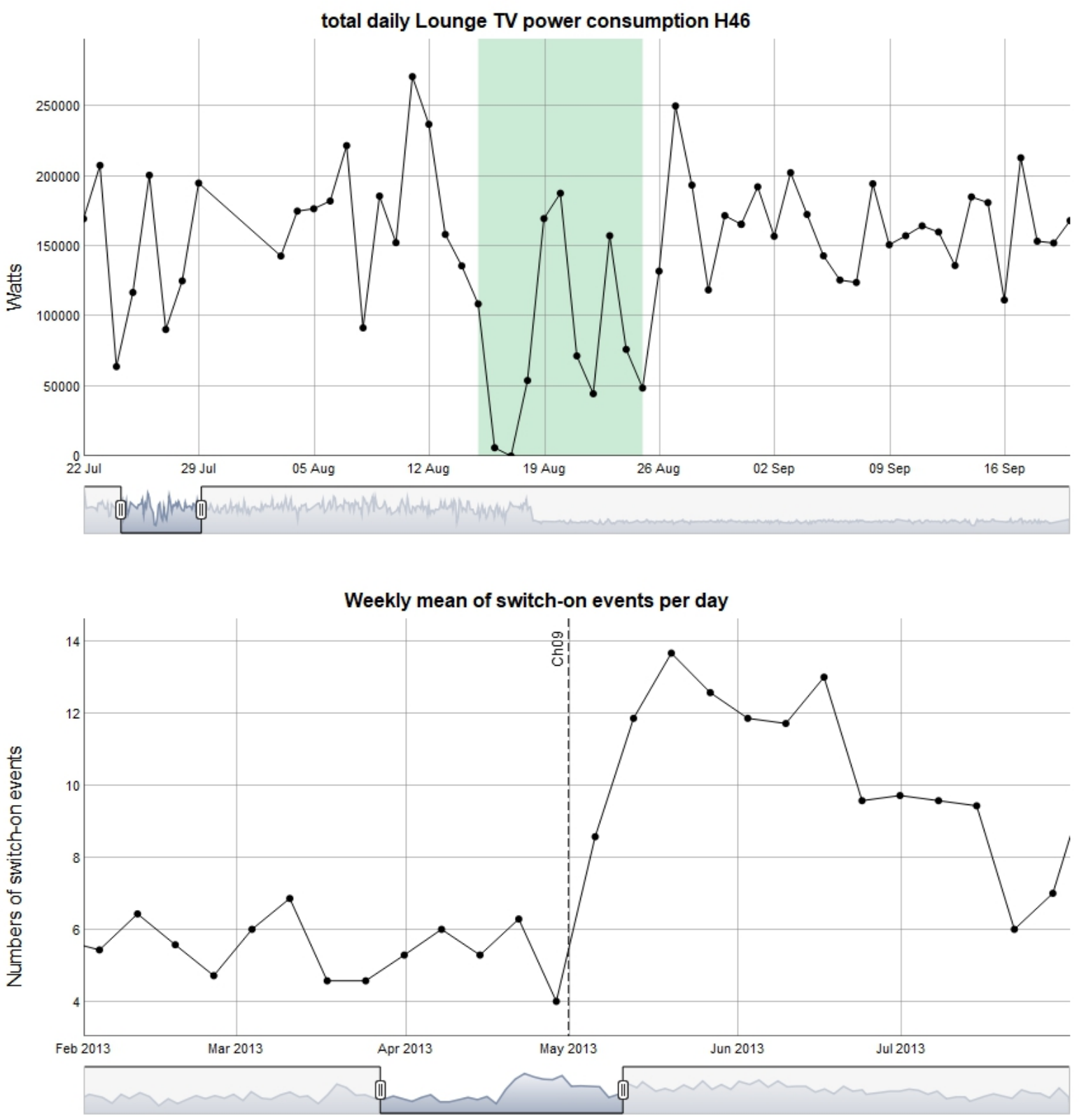

Fig. 4. Daily TV power consumption (Watts) in the upper plot evidences vacation period (shaded band). Kettle weekly mean switch-on events on the bottom plot demonstrates the persistence of a change event (occurring and the black dashed line) in appliance use.

\section{Discussion}


364 Although the evolving nature of life in the home and the impact of activities on energy consumption 365 has been recognised [57], the identification and recording of specific change events has not. We have reported on one, household over a two-year period. Of the 19 change events recorded, we found these broke down into five logical categories that related to: appliances, digital equipment, the building fabric, occupancy, and changes in space configuration.

Studies have shown the variation in routines and domestic practices vary, and are driven by different values [58] and indeed the resultant energy consumption is equally variable [26]. Normality is therefore difficult to define because it depends on the values, practices and contingent behaviour of the occupants, in response to external socially driven factors [59]. The method presented avoids this problem by determining normality given a point in time, and comparing future behaviour to that point: rooting the effect of change on a tangible basis for the householder.

\subsection{Performance of the method}

The method correctly identified $78 \%$ of the recorded changes in the household, but requires a number of measurements to achieve this level of success, but it was able to discern change events from the noise in the measurements. Out of the available measurements, we found that the hot water consumption was the most successful followed by the kettle. It was surprising how similar changes, in consecutive years were detected in different measurements at different granularities of signal. It seems that while the methods can identify changes, using it for 'diagnosis', i.e. getting to the bottom of what caused it will be more problematic, as reported in fault detection and diagnosis research. In this home energy application, it suggests that the context to the change will be important in determining its cause, and that is likely to need engagement by the householder to resolve. The high performance of the kettle as an indicator of change is positive given the ease of monitoring appliance power over the measurement of fluids: we installed an in-line flow meter to the cold feed of the combination boiler to measure hot water consumption in this house as well. The method did generate some responses that were not verified by the reporting: for example, one such period was over the festive season of Christmas, where we might expect there to be a change (increased consumption), but this was not reported by householders. We did find coincidental effects 
of change events difficult to differentiate: for example and vacation by one family member just after

392 the arrival of the new baby. However, the 'false alarm rate' is extremely low meaning the method is

393 very robust and appears to indicate the most significant changes.

\section{$394 \quad$ 5.2. Time-bound and event driven changes}

395 We observed two principle characteristics in the occurring change events: those that were time-bound; and those that were event driven. The time-bound changes in this study related to vacation periods, and we observed a temporary change that returned to normal at the end of the period.

We found that the event driven changes can be different. An event can be the replacement of a TV, and we may or may not see any difference in either the patterns or level of consumption. The arrival of a new baby is a significant event and we observed an extended period of change, eventually settling back to a normal state. The identification of change was driven by increased consumption, however the household then settled to this 'new-normal' state where consumption was higher. This is important for two reasons: it evidences that the increase in consumption is driven by irreconcilable change in the household that forces the occupants to adjust their routines and habits; and, it highlights that the method can determine when the normal state has been reached after change has occurred, but it is blind to whether the state is equivalent to the previous normal state or whether it

407 has shifted to a new-normal state, and hence dictates that a secondary check is made to verify absolute changes in the state of consumption.

\subsection{Data processing framework}

410 The monitoring systems used here were cumbersome and were many devices placed in the home.

411 Although the cost of measurement tends to reduce over time, minimising the cost and complexity of 412 systems will be important for widespread adoption [60]. There is significant potential for the CPD methods described here to augment energy disaggregation systems that can identify the consumption of individual appliances from the incoming mains supply, where there has been recent developments based on artificial neural networks [61] that outperform existing Factorial Hidden Markov Models

416 (FHMM). There is also advantage in context-related information based on low frequency data over

417 the more typical high frequency methods due to the attendant reductions in sensor cost [62]. 
418 Understanding which measurements are the most effective for change identification in this work led 419 us to establish a useful framework that relates measurements to the features that will be captured on 420 which statistical decision making will be based. We found that this tends towards a somewhat finite 421 set of choices driven by the practicality and expense of measurements and the correct sensitivity and 422 statistical quality of the information contained in the data.

423 Fig. 4 depicts the framework, where the levels requiring consideration are the collection of the raw data (RD), establishing the measurements to take (incoming power, temperature, etc.) and the control volumes $(\mathrm{CV})$, or the object to which the measurements are associated (house, appliance, etc.), understanding the appropriate granularity of the signal (GR), i.e. how the measurement is adapted (i.e. consumption per day) and what features will be searched for in the data, (FE) and finally the basis of the statistical test applied. The framework presented attempts to systematically capture these options and is presented here as an aide to others working in this area.

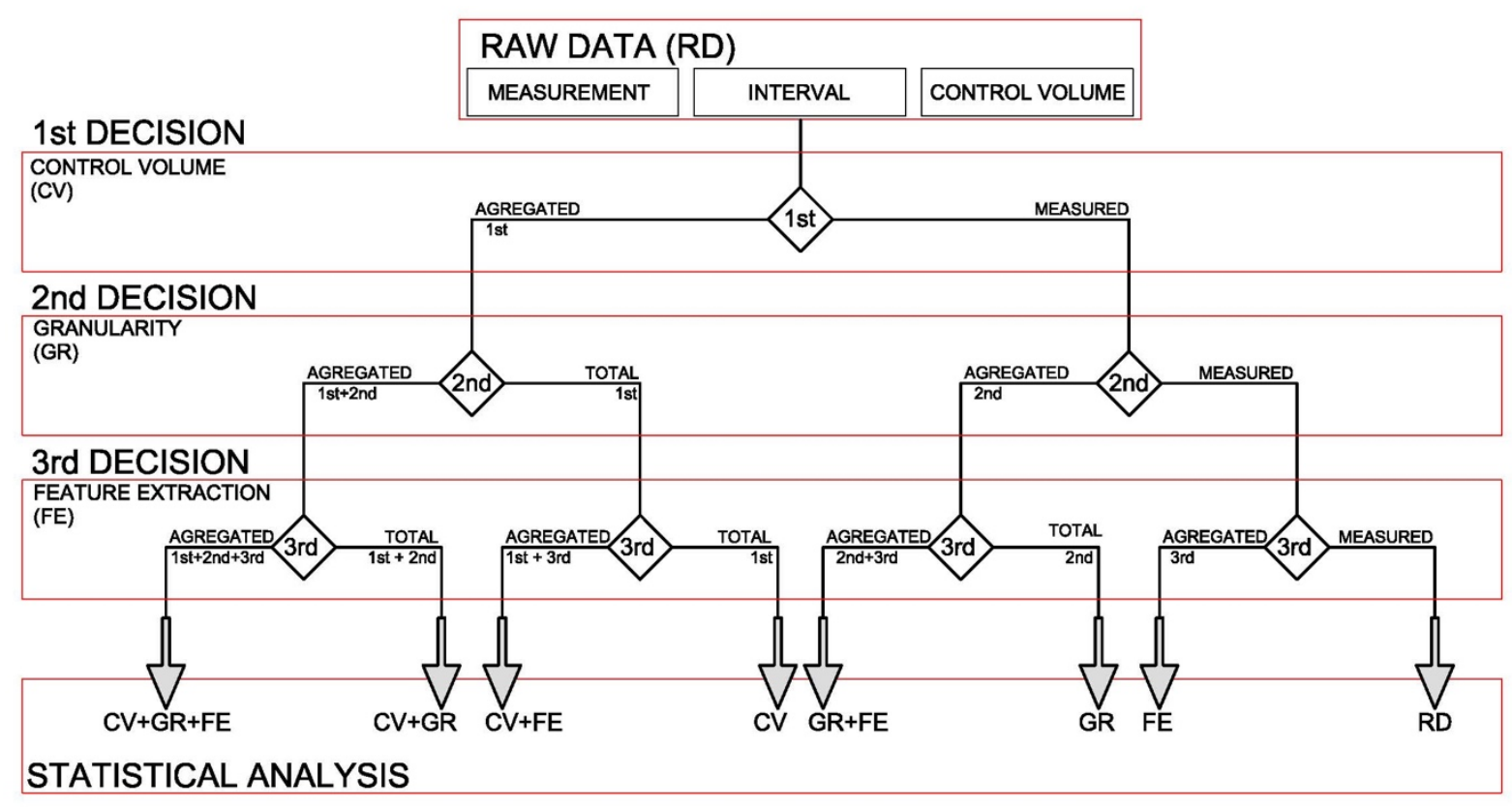

431 Fig. 5. Decision process to select data characteristics for analysis from measurements.

\section{6. Conclusions}

433 The contribution of the work is the introduction of a step-by-step methodology to detect changes in

434 lifestyle and occupancy in the home using smart home energy data and statistical quality control

435 procedures. The method investigated data collected over 24 months in a family home and the 
sensitivity of each measurement as a signal to evidence change was tested at different granularities.

437 The changes recorded in the households included alterations to the space layout, vacation periods,

438 replacement of appliances and the arrival of a baby. The study demonstrated the significant volume of

439 changes that affect the household: one house, two years, five people, 19 changes - almost one change

440 per month.

441 The available measurement data was found to be highly autocorrelated although this problem was resolved by application of an ARIMA model and using the residuals as the signal. The approach was able to identify $78 \%$ of the changes that occurred in the home during the monitoring period. The work also demonstrated the 'normal' consumption level can shift after a change has occurred to a 'newnormal' state and that this can be persistent, suggesting that new routines are being adopted in the home, in the observed case, resulting in higher consumption.

The statistical quality control methods investigated here need to be validated by further work, using in a larger sample to better understand its full potential, but they were demonstrated to be both robust and sensitive to changes. They show great promise in helping the householder to engage with their actions in the home to understand the energy consequences, and numerical methods such as these could easily be scaled up to form the basis of new energy products and services that can add value to existing and future smart meter and home energy monitoring systems.

\section{Acknowledgments}

The data used to underpin this has been produced under the LEEDR: Low Effort Energy Demand Reduction Project based at Loughborough University, UK (EPSRC Grant Number EP/I000267/1).

\section{References}

457 [1] G.T. Gardner, P.C. Stern, Environmental problems and human behavior., Allyn \& Bacon, 1996.

458 [2] J.E. Morrissey, S. Axon, R. Aiesha, J. Hillman, A. Revez, B. Lennon, Identification and Behaviour Change Initiatives, 2016.

[3] W. Abrahamse, L. Steg, C. Vlek, T. Rothengatter, A review of intervention studies aimed at household energy conservation, J. Environ. Psychol. 25 (2005) 273-291.

[4] E. Shove, Converging Conventions of Comfort, Cleanliness and Convenience, J. Consum. Policy. 26 (2003) 395-418.

[5] K. Steemers, G.Y. Yun, Household energy consumption: A study of the role of occupants, Build. Res. Inf. (2009). doi:10.1080/09613210903186661.

] P. Cosar-Jorda, R.A. Buswell, V.A. Mitchell, Determining of the role of ventilation in residential energy 
demand reduction using a heat-balance approach, Build. Environ. (2018).

M. Shipworth, S.K. Firth, M.I. Gentry, A.J. Wright, D.T. Shipworth, K.J. Lomas, Central heating thermostat settings and timing: building demographics, Build. Res. Inf. 38 (2010) 50-69.

[8] S. Pink, K.L. Mackley, R. Moroşanu, Hanging out at home: Laundry as a thread and texture of everyday life, Int. J. Cult. Stud. (2015). doi:10.1177/1367877913508461.

[9] D. Yan, W. O’Brien, T. Hong, X. Feng, H. Burak Gunay, F. Tahmasebi, A. Mahdavi, Occupant behavior modeling for building performance simulation: Current state and future challenges, Energy Build. (2015). doi:10.1016/j.enbuild.2015.08.032.

[10] T. Hargreaves, Practice-ing behaviour change: Applying social practice theory to pro-environmental behaviour change, J. Consum. Cult. (2011). doi:10.1177/1469540510390500.

[11] S. Aminikhanghahi, D.J. Cook, A survey of methods for time series change point detection, Knowl. Inf.

[12] Y. Strengers, Negotiating everyday life: The role of energy and water consumption feedback, J. Consum. Cult. 11 (2011) 319-338. doi:10.1177/1469540511417994.

[13] HM Government, Industrial Strategy: Building a Britain fit for the future, (2017). https://assets.publishing.service.gov.uk/government/uploads/system/uploads/attachment_data/file/66456 3/industrial-strategy-white-paper-web-ready-version.pdf?_ga=2.176869477.131331705.15669053901346621436.1566905390 .

[14] Protocol Kyoto, United Nations framework convention on climate change, Kyoto Protoc. Kyoto. 19 (1997).

[15] S.J. Darby, Smart electric storage heating and potential for residential demand response, Energy Effic. (2018). doi:10.1007/s12053-017-9550-3.

[16] Department for Business Energy \& Industrial Strategy, Energy Consumption in the UK, 2016.

[17] European Commission, Good practice in energy efficiency: For a sustainable, safer and more competitive Europe, Clean Energy All Eur. (2017). doi:10.1086/304912.

[18] K.X. Perez, K. Cetin, M. Baldea, T.F. Edgar, Development and analysis of residential change-point models from smart meter data, Energy Build. (2017). doi:10.1016/j.enbuild.2016.12.084.

[19] K. Gram-Hanssen, New needs for better understanding of household's energy consumption-behaviour, lifestyle or practices?, Archit. Eng. Des. Manag. 10 (2014) 91-107.

[20] E.R. Frederiks, K. Stenner, E. V. Hobman, M. Fischle, Evaluating energy behavior change programs using randomized controlled trials: Best practice guidelines for policymakers, Energy Res. Soc. Sci. (2016). doi:10.1016/j.erss.2016.08.020.

[21] L. Gynther, I. Mikkonen, A. Smits, Evaluation of European energy behavioural change programmes, Energy Effic. 5 (2012) 67-82.

[22] Behavioural Insights Team, Behaviour Change and Energy Use, Cabinet Off. London(Available at)/Http//Www.Cabinetoffice.Gov.Uk/Resourcelibrary/Behaviour-Change-and-Energy-UseS. (2011).

[23] B. Dahlbom, H. Greer, C. Egmond, R. Jonkers, Changing Energy Behaviour Guidelines for Behavioural Change Programmes, Madrid, 2009. https://ec.europa.eu/energy/intelligent/projects/sites/ieeprojects/files/projects/documents/behave_guidelines_for_behavioural_change_programmes_en.pdf.

[24] S. Pink, K.L. Mackley, Video and a Sense of the Invisible: Approaching Domestic Energy Consumption 
Through the Sensory Home, Sociol. Res. Online. 17 (2012) 3.

[25] F. Belaïd, S. Bakaloglou, D. Roubaud, Direct rebound effect of residential gas demand: Empirical evidence from France, Energy Policy. 115 (2018) 23-31. doi:https://doi.org/10.1016/j.enpol.2017.12.040.

[26] C. Wilson, T. Hargreaves, R. Hauxwell-Baldwin, Benefits and risks of smart home technologies, Energy Policy. 103 (2017) 72-83.

[27] N. Mogles, I. Walker, A.P. Ramallo-González, J. Lee, S. Natarajan, J. Padget, E. Gabe-Thomas, T. Lovett, G. Ren, S. Hyniewska, E. O’Neill, R. Hourizi, D. Coley, How smart do smart meters need to be?, Build. Environ. 125 (2017) 439-450. doi:https://doi.org/10.1016/j.buildenv.2017.09.008.

[28] T. Hargreaves, M. Nye, J. Burgess, Making energy visible: A qualitative field study of how householders interact with feedback from smart energy monitors, Energy Policy. 38 (2010) 6111-6119.

[29] S.J. Darby, Smart technology in the home: time for more clarity, Build. Res. Inf. 46 (2018) 140-147.

[30] T. Jackson, Motivating sustainable consumption, Sustain. Dev. Res. Netw. 29 (2005) 30. http://research3.fit.edu/sealevelriselibrary/documents/doc_mgr/922/Jackson. 2005. Motivating Sustainable Consumption.pdf (accessed September 20, 2018).

[31] J. Lynham, K. Nitta, T. Saijo, N. Tarui, Why does real-time information reduce energy consumption?, Energy Econ. (2016). doi:10.1016/j.eneco.2015.11.007.

[32] S. Owens, L. Driffill, How to change attitudes and behaviours in the context of energy, Energy Policy. 36 (2008) 4412-4418. doi:10.1016/J.ENPOL.2008.09.031.

[33] J.E. Seem, Using intelligent data analysis to detect abnormal energy consumption in buildings, Energy Build. 39 (2007) 52-58. doi:10.1016/j.enbuild.2006.03.033.

[34] J. Hyvärinen, S. Kärk, eds., Building optimization and fault diagnosis source book. IEA Annex, 25, Technical Research Centre of Finland, VTT Building Technology, Espoo, Finland, 1996. http://www.iea-ebc.org/Data/publications/EBC_Annex_25_source_book.pdf.

[35] I. Richardson, M. Thomson, D. Infield, C. Clifford, Domestic electricity use: A high-resolution energy demand model, Energy Build. 42 (2010) 1878-1887.

[36] R.J. Meyers, E.D. Williams, H.S. Matthews, Scoping the potential of monitoring and control technologies to reduce energy use in homes, Energy Build. 42 (2010) 563-569.

[37] Y. Agarwal, B. Balaji, S. Dutta, R.K. Gupta, T. Weng, Duty-cycling buildings aggressively: the next frontier in HVAC control, Proc. 10th Int. Conf. Inf. Process. Sens. Networks. (2011) 246-257. doi:10.1.1.303.5773.

[38] M. Weiss, M.K. Patel, M. Junginger, K. Blok, Analyzing price and efficiency dynamics of large appliances with the experience curve approach, Energy Policy. 38 (2010) 770-783.

[39] Y. Agarwal, B. Balaji, R. Gupta, J. Lyles, M. Wei, T. Weng, Occupancy-driven energy management for smart building automation, in: Proc. 2nd ACM Work. Embed. Sens. Syst. Energy-Efficiency Build. BuildSys '10, ACM Press, New York, New York, USA, 2010: p. 1. doi:10.1145/1878431.1878433.

[40] Z. Yu, F. Haghighat, B.C.M. Fung, H. Yoshino, A decision tree method for building energy demand modeling, Energy Build. (2010). doi:10.1016/j.enbuild.2010.04.006.

[41] I. Richardson, M. Thomson, D. Infield, A high-resolution domestic building occupancy model for energy demand simulations, Energy Build. 40 (2008) 1560-1566. 
[42] F. Haldi, D. Robinson, On the behaviour and adaptation of office occupants, Build. Environ. (2008). doi:10.1016/j.buildenv.2008.01.003.

[43] P. Bacher, H. Madsen, Identifying suitable models for the heat dynamics of buildings, Energy Build. (2011). doi:10.1016/j.enbuild.2011.02.005.

[44] M. Santamouris, G. Mihalakakou, P. Patargias, N. Gaitani, K. Sfakianaki, M. Papaglastra, C. Pavlou, P. Doukas, E. Primikiri, V. Geros, M.N. Assimakopoulos, R. Mitoula, S. Zerefos, Using intelligent clustering techniques to classify the energy performance of school buildings, Energy Build. (2007). doi:10.1016/j.enbuild.2006.04.018.

[45] W.F. van Raaij, T.M.M. Verhallen, Patterns of residential energy behavior, J. Econ. Psychol. (1983). doi:10.1016/0167-4870(83)90047-8.

[46] K.T. Papakostas, B.A. Sotiropoulos, Occupational and energy behaviour patterns in Greek residences, Energy Build. (1997).

[47] G. Sprint, D. Cook, R. Fritz, M. Schmitter-Edgecombe, Detecting Health and Behavior Change by Analyzing Smart Home Sensor Data, in: 2016 IEEE Int. Conf. Smart Comput. SMARTCOMP 2016, 2016. doi:10.1109/SMARTCOMP.2016.7501687.

[48] S. Aminikhanghahi, D.J. Cook, Enhancing activity recognition using CPD-based activity segmentation, Pervasive Mob. Comput. (2019). doi:10.1016/j.pmcj.2019.01.004.

[49] N.C. Krishnan, D.J. Cook, Activity recognition on streaming sensor data, Pervasive Mob. Comput. (2014). doi:10.1016/j.pmcj.2012.07.003.

[50] S. Wei, R. Jones, P. de Wilde, Driving factors for occupant-controlled space heating in residential buildings, Energy Build. 70 (2014) 36-44. doi:10.1016/j.enbuild.2013.11.001.

[51] R. Buswell, L. Webb, P. Cosar-Jorda, D. Marini, S. Brownlee, M. Thomson, S.-H. Yang, R. Kalawsky, LEEDR project home energy dataset, (2018). doi:10.17028/rd.lboro.6176450.v1.

[52] E. Kulinskaya, J. Koricheva, Use of quality control charts for detection of outliers and temporal trends in cumulative meta-analysis, Res. Synth. Methods. 1 (2010) 297-307. doi:10.1002/jrsm.29.

[53] L. Scrucca, qcc: An R package for quality control charting and statistical process control, R News. 4 (2004) 11-17. http://cran.r-project.org/doc/Rnews/.

[54] R.J. Hyndman, Y. Khandakar, Automatic time series forecasting: The forecast package for R, J. Stat. Softw. 27 (2008) C3-C3. doi:10.18637/jss.v027.i03.

[55] D. Montgomery, Introduction to statistical quality control, 2009. doi:10.1002/15213773(20010316)40:6<9823::AID-ANIE9823>3.3.CO;2-C.

[56] I. Barbeito, S. Zaragoza, J. Tarrío-Saavedra, S. Naya, Assessing thermal comfort and energy efficiency in buildings by statistical quality control for autocorrelated data, Appl. Energy. 190 (2017) 1-17. doi:10.1016/j.apenergy.2016.12.100.

[57] S. Pink, K.L. Mackley, R. Morolcsanu, Hanging out at home: Laundry as a thread and texture of everyday life, Int. J. Cult. Stud. 18 (2015) 209-224.

[58] BEIS, The Clean Growth Strategy: Leading the way to a low carbon future, Dep. Business, Energy Ind. Strateg. (2017). https://www.gov.uk/government/publications/clean-growth-strategy.

[59] V. Haines, V. Mitchell, A persona-based approach to domestic energy retrofit, Build. Res. Inf. 42 (2014) $462-476$. 
[60] Eon SE, Annual Report 2017, n.d. https://www.eon.com/content/dam/eon/eon-com/investors/annualreport/EON_GB17_EN.pdf (accessed December 21, 2018).

589

[61] N. Symeonidis, C. Nalmpantis, D. Vrakas, A benchmark framework to evaluate energy disaggregation solutions, in: Commun. Comput. Inf. Sci., 2019. doi:10.1007/978-3-030-20257-6_2.

591 [62] F. Paradiso, F. Paganelli, D. Giuli, S. Capobianco, Context-based energy disaggregation in smart homes, Futur. Internet. (2016). doi:10.3390/fi8010004.

593

594

[REF BRI Paper] R. Buswell, L. Webb, V. Mitchell \& K. Leder Mackley, Multidisciplinary research: should

597 